\title{
Measuring adaptive expertise: development and validation of an instrument
}

\author{
Citation for published version (APA):
}

Bohle Carbonell, K., Könings, K. D., Segers, M. S. R., \& van Merriënboer, J. J. G. (2016). Measuring adaptive expertise: development and validation of an instrument. European Journal of Work and Organizational Psychology, 25(2), 167-180. https://doi.org/10.1080/1359432X.2015.1036858

\section{Document status and date:}

Published: 03/03/2016

DOI:

10.1080/1359432X.2015.1036858

Document Version:

Publisher's PDF, also known as Version of record

\section{Document license:}

Taverne

\section{Please check the document version of this publication:}

- A submitted manuscript is the version of the article upon submission and before peer-review. There can be important differences between the submitted version and the official published version of record.

People interested in the research are advised to contact the author for the final version of the publication, or visit the DOI to the publisher's website.

- The final author version and the galley proof are versions of the publication after peer review.

- The final published version features the final layout of the paper including the volume, issue and page numbers.

Link to publication

\footnotetext{
General rights rights.

- You may freely distribute the URL identifying the publication in the public portal. please follow below link for the End User Agreement:

www.umlib.nl/taverne-license

Take down policy

If you believe that this document breaches copyright please contact us at:

repository@maastrichtuniversity.nl

providing details and we will investigate your claim.
}

Copyright and moral rights for the publications made accessible in the public portal are retained by the authors and/or other copyright owners and it is a condition of accessing publications that users recognise and abide by the legal requirements associated with these

- Users may download and print one copy of any publication from the public portal for the purpose of private study or research.

- You may not further distribute the material or use it for any profit-making activity or commercial gain

If the publication is distributed under the terms of Article $25 \mathrm{fa}$ of the Dutch Copyright Act, indicated by the "Taverne" license above, 
(1)

\section{Measuring adaptive expertise: development and validation of an instrument}

Katerina Bohle Carbonell, Karen D. Könings, Mien Segers \& Jeroen J. G. van Merriënboer

To cite this article: Katerina Bohle Carbonell, Karen D. Könings, Mien Segers \& Jeroen J. G. van Merriënboer (2016) Measuring adaptive expertise: development and validation of an instrument, European Journal of Work and Organizational Psychology, 25:2, 167-180, DOI: $10.1080 / 1359432 X .2015 .1036858$

To link to this article: https://doi.org/10.1080/1359432X.2015.1036858

\section{Published online: 08 May 2015.}

\section{Submit your article to this journal $\sqsubset$}

Llll Article views: 1210

Q View related articles ¿

View Crossmark data ¿

4

Citing articles: 13 View citing articles 


\title{
Measuring adaptive expertise: development and validation of an instrument
}

\author{
Katerina Bohle Carbonell*, Karen D. Könings, Mien Segers and Jeroen J. G. van Merriënboer \\ Department of Educational Research and Development, Faculty of Health, Medicine, and Life Sciences, Maastricht University, PO Box \\ 616, 6200LM Maastricht, The Netherlands
}

(Received 22 August 2014; accepted 29 March 2015)

\begin{abstract}
Individuals with adaptive expertise possess the skills to deal with novel problems. Whereas this concept has been around since the mid-1980s, no instrument exists that provides a good operationalization of the theoretical construct. This inhibits the further development of research on adaptive expertise and the evaluation of employees' adaptive expertise levels. Adaptive expertise has been unanimously described as a composition of domain-specific and innovative skills. Some researchers argue that metacognitive skills are also crucial. This study aimed to establish whether an instrument measuring adaptive expertise is composed of these three dimensions. In addition, it was tested whether such an instrument is influenced by task variety and work experience, as previously reported in literature. A sample of 383 professionals and graduates were used to test the Adaptive Expertise Inventory. Through exploratory factor analysis (EFA), (E/CFA), and confirmatory factor analysis (CFA), the quality of the instrument was evaluated. Good model fit was achieved. The final instrument consisted of two dimensions - i.e., domain-specific and innovative skills - with five items each. Regression analysis showed that not work experience, but task variety is related to level of adaptive expertise. The Adaptive Expertise Inventory proved to be a valid instrument for measuring adaptive expertise.
\end{abstract}

Keywords: adaptive expertise; innovative skills; task variety; validation; CFA

Employees with adaptive expertise are able to effectively deal with situations which are uncommon to their work domain; while doing so, moreover, they create new knowledge and methods (Barnett \& Koslowski, 2002; Hatano \& Oura, 2003; Mylopoulos \& Regehr, 2009). Companies need employees with adaptive expertise, because the frequent creation of new knowledge and methods helps them maintain their competitive advantage (Nahapiet \& Ghoshal, 1998). However, the fact that employees are not fully aware of their adaptive expertise (Mylopoulos \& Scardamalia, 2008) and therefore do not adequately share the newly created knowledge and methods with colleagues constitutes a challenge.

According to the literature, adaptive expertise has three components: (1) domain-specific skills, (2) metacognitive skills, and (3) innovative skills (Crawford, Schlager, Toyama, Riel, \& Vahey, 2005; Hatano \& Inagaki, 1986; Hatano \& Oura, 2003). It has often been contrasted with routine expertise (Hatano \& Inagaki, 1986), which is expert performance without the ability to perform at a very high level in situations that are not representative of their domain.

In the workplace literature, several instruments that measure some form of adaptability on the job have been described. These instruments measure the ability to adjust behaviour in response to changes in the situation, but do not measure adaptive expertise. Charbonnier-Voirin and Roussel (2012) and Pulakos, Arad, Donovan, and Plamondon (2000), for example, developed instruments with which the ability to adapt to changes in the work environment could be assessed. These instruments assess the adaptation to various forms of change (e.g., physical adaptation, interpersonal adaptation). They address a great many sources of change, ranging from simple fluctuations in the amount of work (e.g., the ability to handle work stress) to common sources of change (e.g., interpersonal adaptability). Hence, these instruments fall short of measuring adaptive expertise, because they do not specifically measure adaptation to non-standard situations.

van der Heijden (2000) developed an instrument that measures expert performance. While this instrument addresses the dimension of expertise, the author perceived that meeting and even exceeding achievement standards is of utmost importance to experts. This leaves less scope for the acquisition of new knowledge and skills, which is crucial for the development of adaptive expertise (Hatano \& Inagaki, 1986).

In the educational literature, Fisher and Peterson (2001) documented on an instrument that measures attitudes towards adaptive expertise. Whereas, at face value,

\footnotetext{
*Corresponding author. Email: k.bohlecarbonell@maastrichtuniversity.nl 
this instrument may seem to measure adaptive expertise, it actually provides information about how an individual feels about the need to be adaptive, not about whether the individual is able and willing to adapt his or her knowledge and methods to solve the situation.

To conclude, present-day instruments do not attempt to measure adaptive expertise, as they fail to satisfy the theoretical conceptualization of adaptive expertise. The aim of developing an instrument that does meet this requirement, therefore, is twofold: (1) to further the research on adaptive expertise by providing an instrument that makes the three dimensions of adaptive expertise (i.e., domain-specific, metacognitive, and innovative skills) operational, and (2) to help companies measure their workforce's readiness to deal with situations that are not representative of their domain. In the following sections, the concept of adaptive expertise and its three dimensions will be further explained. The ensuing framework is consequently used to analyse the existing instruments that measure adaptation at the workplace. The same framework is used to guide the creation of the new instrument. Through several analyses, the instrument's construct validity will be assessed. The paper concludes with an appraisal of the instrument's potential to measure adaptive expertise and with recommendations for further research.

\section{Adaptive expertise}

Employees with a high level of adaptive expertise are experts who "can be characterized by their flexible, innovative, and creative competencies within the domain" (Hatano \& Oura, 2003, p. 28). They are able to detect anomalies in their tasks and are consequently alerted when the skills and rule-based behaviour that guide their decision-making are likely to result in suboptimal behaviour (Olsen \& Rasmussen, 1989). Individuals who do not show adaptive expertise, but who are still experts in their domains, are said to possess routine expertise (Hatano \& Oura, 2003). Adaptive expertise is built on routine expertise, as both forms of expertise contain the ability to perform standard tasks in the domain without errors. The difference only becomes apparent when confronted with a non-standard situation: Individuals with adaptive expertise possess a more extensive and integrated knowledge base than do individuals with routine expertise (Hatano \& Inagaki, 1986). This helps them to determine when not to rely on their automatic processes; when this happens, they can "slow down" and make conscious efforts to deal with the problem. It follows that they abandon skill- and rule-based decision-making (Olsen \& Rasmussen, 1989; Sonnentag, Niessen, \& Volmer, 2006) and spend time building a mental model of the situation, in which they draw analogies between standard and novel situations (Barnett \& Koslowski, 2002; Chi, 2011; Gentner et al., 1997; Wineburg, 1998).

This description of adaptive expertise indicates that it is situated within the field of research on professional expertise, not on traditional expertise. It is a developmental process that is being propelled by problem-solving skills (Tynjälä, Nuutinen, Eteläpelto, Kirjonen, \& Remes, 1997). The concept of adaptive expertise focuses on one of the aspects of professional expertise (e.g., growth) and does not touch upon other aspects (e.g., social recognition) (Bohle Carbonell, Stalmeijer, Könings, Segers, \& Van Merriënboer, 2014). Consequently, characteristics of traditional expertise research (e.g., repeated high performance, standardized tasks) play a lesser role compared to the need for non-standard but realistic tasks that elicit the problemsolving skills of individuals with adaptive expertise.

To better understand the problem-solving skills of individuals with adaptive expertise, insights from the cognitive perspective on professional decision-making are used. One important factor is domain validity, which refers to the presence or absence of regularities in a domain (Kahneman \& Klein, 2009; Shanteau, 1992). Domains that are characterized by a high frequency of valid cues coupled with quick feedback provide experts with a greater amount of learning experiences. In such a high-validity environment, experts can be certain that the presence of one or more specific cues will lead to specific consequences. This causal structure benefits the development of fast and automated decision-making skills, characteristic of individuals with routine and adaptive expertise.

However, in moving from routine expertise to adaptive expertise, high-validity environments slow down the development of adaptive expertise, as individuals working in those environments are infrequently presented with non-standard situations and thus are not presented with opportunities to reflect on their expertise and its match with the problem at hand (Dane, 2010) and the need to develop new performance standards (Bransford \& Schwartz, 2009). Therefore, experts in those domains develop a penchant for perceiving expert knowledge as "static". They do not have the epistemological perspective of individuals with high levels of adaptive expertise who regard expertise knowledge as "dynamic" and evolving.

\section{The dimensions of adaptive expertise}

The concept of adaptive expertise consists of three dimensions, as depicted in Figure 1: domain-specific skills, metacognitive skills, and innovative skills. The first two

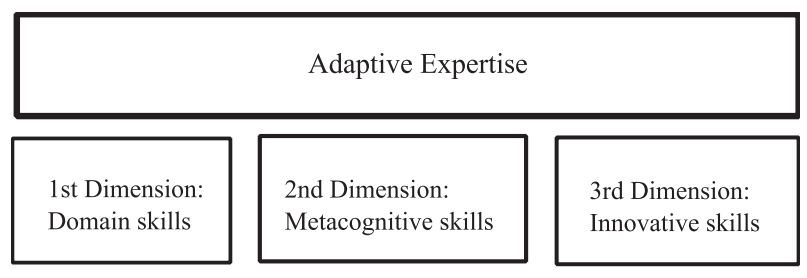

Figure 1. Dimensions of adaptive expertise. 
dimensions are said by several researchers to be the foundations for adaptive expertise, as domain-specific skills and metacognitive skills are already basic components of routine expertise (Feltovich, Prietula, \& Ericsson, 2006), which is a prerequisite for adaptive expertise. The literature on adaptive expertise, however, is not clear on the exact role metacognitive skills play in the development of adaptive expertise. While some judge it to be a part of routine expertise (Hatano \& Oura, 2003; Varpio, Schryer, \& Lingard, 2009), others suggest that individuals with adaptive expertise possess better metacognitive skills than those with routine expertise (Crawford et al., 2005; Fisher \& Peterson, 2001; Martin, Petrosino, Rivale, \& Diller, 2006; Martin, Rivale, \& Diller, 2007; Mylopoulos \& Woods, 2009). Unfortunately, no evidence exists for either one of these positions (Bohle Carbonell et al., 2014). Nevertheless, what is clear from the literature is that routine and adaptive expertise do not oppose each other; rather, adaptive expertise builds on routine expertise (Schwartz, Bransford, \& Sears, 2005).

A difference noted by researchers in domain-specific skills between individuals with adaptive and routine expertise is their epistemological stand. Individuals with adaptive expertise view their body of knowledge as dynamic and evolving, whereas individuals with routine expertise perceive it as static (Crawford et al., 2005; Fisher \& Peterson, 2001). Consequently, individuals with routine expertise focus less on the continuous acquisition of new domain knowledge and skills. Individuals with adaptive expertise do not mind making errors (Hatano \& Inagaki, 1986), as these may lead to more extensive and integrated domain knowledge; it also teaches them what not to do in particular situations. Making errors provides individuals with opportunities to learn, especially when they understand the sources of their errors and hence learn how to avoid them (Bell \& Kozlowski, 2008; Hughes et al., 2013).

With respect to the dimension of innovative skills, studies have reported that individuals with adaptive expertise possess high cognitive flexibility and deep thinking skills (Allworth \& Hesketh, 1999; Barnett \& Koslowski, 2002; Bell \& Kozlowski, 2008; Reder \& Schunn, 1999; Stokes, Schneider, \& Lyons, 2010). These skills enable individuals with adaptive expertise (1) to view situations outside of their context and thus to draw analogies to other situations they have experience with, and (2) to decompose their knowledge into its smallest building blocks in order to be able to reassemble these differently in order to deal with novel situations.

An outcome of adaptive expertise is the creation of new knowledge or methods. As described above, adaptive expertise is the ability to excel in situations that are not representative of the individual's domain. To be able to solve non-standard problems, individuals have to transform their current body of knowledge and methods of working. As a result of this, adaptive expertise leads to the creation of something new. This may be new knowledge (declarative, procedural, or conditional; Alexander, Schallert, \& Hare, 1991) or a new method of working.

\section{Existing instruments and their limitations}

In order to measure adaptive expertise properly, an instrument should meet several criteria. Such criteria for the assessment of an instrument's robustness include the number and content of subscales and the wording of items.

Regarding the subscales, an instrument that assesses adaptive expertise should contain at least two of these: one for the domain-specific skills and one for innovative skills. Given the current uncertainty about the place of metacognitive skills in the concept of adaptive expertise, it is argued that metacognitive skills can be part of an instrument that measures adaptive expertise, but this is not imperative.

Several requirements apply to the wording of the items. First, items referring to domain-specific skills should be phrased according to the epistemological viewpoint that knowledge is dynamic. This accounts for the social and cognitive perspective of expertise. The first perspective recognizes that the designation of expert status and expert decision-making is dependent on peers (Grenier \& Kehrhahn, 2008; Shanteau, 1992). Domain knowledge is dynamic, as what is considered to be expert knowledge varies with the individuals working in a domain and new domain knowledge. The epistemological standpoint of individuals with adaptive expertise highlights their awareness of the fractionation of their expertise (Kahneman \& Klein, 2009). Second, items for all subscales need to refer to the workplace, as individuals with high levels of adaptive expertise are most likely to demonstrate this performance in their domain. Third, the items in the instrument need to refer to novel situations, as individuals with adaptive expertise demonstrate their ability to detect irregularities in the environmental cues when confronted with unfamiliar situations.

Four potential instruments are considered: two set out to measure adaptive performance, one measures attitudes of adaptive expertise, and the fourth measures professional flexibility. Table 1 indicates how each instrument aligns with our conceptualization of adaptive expertise.

First, Pulakos et al. (2000) created an instrument that measures adaptive performance. Adaptive performance is the effort of an individual to realign his or her behaviour with new demands at the workplace (Chan, 2000). However, if we relate this instrument to the operationalization of adaptive expertise, it becomes clear that the instrument only meets two out of six criteria: it does not contain subscales measuring domain-specific skills and metacognitive skills, nor does it include the epistemological perspective of adaptive expertise and the required focus on novel situations. 
Table 1. Critiera for measuring adaptive expertise.

\begin{tabular}{|c|c|c|c|c|}
\hline \multirow[b]{2}{*}{ Name of measured concept } & Pulakos et al. (2000) & $\begin{array}{l}\text { Charbonnier-Voirin and } \\
\text { Roussel (2012) }\end{array}$ & \multirow{2}{*}{$\begin{array}{c}\begin{array}{c}\text { Fisher and } \\
\text { Peterson (2001) }\end{array} \\
\begin{array}{c}\text { Attitudes of } \\
\text { adaptive } \\
\text { expertise }\end{array}\end{array}$} & \multirow{2}{*}{$\begin{array}{c}\begin{array}{c}\text { van der } \\
\text { Heijden } \\
(2000)\end{array} \\
\begin{array}{c}\text { Professional } \\
\text { flexibility }\end{array}\end{array}$} \\
\hline & Adaptive performance & Adaptive performance & & \\
\hline \multicolumn{5}{|c|}{ Requirements about the number and content of subscales } \\
\hline $\begin{array}{l}\text { 1. Does it have a subscale referring to } \\
\text { domain skills }\end{array}$ & No & No & No & Yes \\
\hline $\begin{array}{l}\text { 2. Does it contain a subscale referring } \\
\text { to innovative skills }\end{array}$ & Yes & Yes & Yes & Yes \\
\hline $\begin{array}{l}\text { 3. Does it contain a subscale referring } \\
\text { to metacognitive skills (optional) }\end{array}$ & No & No & Yes & Yes \\
\hline \multicolumn{5}{|l|}{ Requirements about the wording of items } \\
\hline $\begin{array}{l}\text { 1. Does the wording of the item } \\
\text { include the epistemological } \\
\text { perspective? }\end{array}$ & No & No & Yes & No \\
\hline 2. Do the items refer to the workplace? & Yes & Yes & No & Yes \\
\hline $\begin{array}{l}\text { 3. Do the items refer to novel } \\
\text { situations? }\end{array}$ & $\begin{array}{c}\text { No, } 1 \text { subscale refers to } \\
\text { uncertain/ unpredictable } \\
\text { situations }\end{array}$ & $\begin{array}{c}\text { No, } 1 \text { subscale refers to } \\
\text { uncertain/ unpredictable } \\
\text { situations }\end{array}$ & Yes & Yes, 2 items \\
\hline
\end{tabular}

Note: The instrument by Pulakos et al. (2000) is not published; thus, judgments are based on the description of subscales.

Second, Charbonnier-Voirin and Roussel (2012) developed a scale with which to measure adaptive performance in organizations. The instrument is based on the taxonomy described by Pulakos et al. (2000). While the instrument clearly aims at the assessment of working professionals' performance and also includes a subscale about innovative skills, it does not address domain-specific or metacognitive skills, the epistemological perspective of adaptive expertise, and the ability to deal with non-standard situations. As with the instrument by Pulakos et al. (2000), uncertain and unpredictable situations are its foci.

Third, Fisher and Peterson (2001) created a tool with which to assess adaptive expertise. The conceptual framework they adopted is one in which adaptive expertise is based on a "conceptual understanding of the skill" (Chi, 2011 , p. 31) and, as the authors state, the focus is on "adaptiveness" and not on expert performance (Fisher \& Peterson, 2001, p. 2). This position resulted in an instrument that measures "disposition or mindset" (Fisher \& Peterson, 2001, p. 4) when solving problems and neglects the level of domain-specific skills necessary to be called an expert. While the instrument developed by Fisher and Peterson (2001) fulfils four out of our six criteria (innovative and metacognitive skills, epistemological perspective, and novel situations), it is void of any reference to the work domain.

Fourth, van der Heijden (2000) documented on an instrument that measures professional flexibility. The author of this instrument deemed achievement orientation an important part of expertise, as she used the degree of perseverance of employees to create a continuum of expertise. Hence, each scale includes items that are phrased in line with this orientation. Achievement orientation is characterized by "a willingness to work hard and persistently on issues that are of particular interest to the individual, perseverance in the face of obstacles, a high level of aspiration, competitiveness and ambition" (van der Heijden, 2000, p. 12). The inclusion of achievement orientation, however, leads to a conceptual framework that contradicts adaptive expertise, which puts far more weight on learning than on achieving. Hence, despite the fact that the instrument includes all the necessary subscales, it fails to meet the requirement related to the wording of the items (i.e., epistemological perspective).

The preceding analysis shows that all of the potential instruments fail to meet at least one criterion. The instruments developed by Fisher and Peterson (2001) and van der Heijden (2000) provide the closest fit to the concept of adaptive expertise. Therefore, these two instruments were selected to serve as the basis for the development of a new instrument. The research objectives were defined accordingly: the first aim was to create an instrument that measures adaptive expertise according to its theoretical conceptualization, as expressed in the six criteria mentioned above. This instrument should assess adaptive expertise by including at least the required subscales of domain-specific and innovative skills. In addition, the items should refer to the epistemological perspective, the workplace, and to novel situations. Second, we aimed to assess construct validity of the instrument using 
exploratory factor analysis (EFA), EFA in the confirmatory factor analysis framework (E/CFA), and confirmatory factor analysis (CFA) to test if the instrument contains two or three dimensions. This will help determine the role of metacognitive skills in the acquisition of adaptive expertise. Third, we sought to assess internal reliability using Cronbach's alpha.

Expertise research has provided evidence that the performance of experts is dependent on the validity of their domain. High-validity environments are domains that present frequent and valid cues and thus provide individuals with ample opportunities to learn the causal relationship between an environmental cue and its consequences. This regularity encourages individuals to learn domain-relevant patterns (Kahneman \& Klein, 2009), but decreases the need for high levels of adaptive expertise. Whether the need for high levels of adaptive expertise rises with decreases in validity, however, was the focus of the fourth research question.

Studies on adaptive expertise have asserted that both general experience and experience with varied tasks have a positive impact on the development of adaptive expertise (Hatano \& Inagaki, 1986; Schwartz et al., 2005). Some evidence exists for this assertion (Barnett \& Koslowski, 2002; Martin \& Schwartz, 2009). Therefore, our fifth aim was to measure criterion validity by testing two hypotheses: (1) if working on varied tasks (task variety) has a positive effect on adaptive expertise, and (2) if number of years of work experience has a positive effect on adaptive expertise.

\section{Method}

\section{Instrument creation}

To design the instrument, we departed from the literature (Burns et al., 2008). We drew items from the scales "metacognitive skills" and "growth and flexibility" of van der Heijden's (2000) instrument. This created a pool of items for the optional subscale of metacognitive skills and the necessary subscale of innovative capacities. We did not use the author's subscale of knowledge and skills, as these items were phrased with an achievement-orientation slant.

From Fisher and Peterson's instrument (2001), we drew items from the scales "multiple perspectives" and "metacognitive self-assessment", with which the pool of items for innovative skills and metacognitive skills was enlarged. The subscale "epistemology" was not used, as it referred to knowledge in general and not to domain knowledge. This yielded a total of 41 initial items. To bring order to those items, these were grouped into domain-specific skills, metacognitive skills, and innovative skills. To reduce the length of the instrument and, with that, the time commitment asked of participants, items were removed where possible: Six items were removed for their redundancy and 11 because they did not fit the concept of adaptive expertise.

The remaining items were analysed for clarity and common reference category. The instrument by van der Heijden (2000) related all items to the participant's work environment, whereas the instrument by Fisher and Peterson (2001) used problems or tasks as a reference category. As the level of adaptive expertise is dependent on the domain, it was decided to change the reference category to "work" or "discipline". The term "work" was chosen instead of "problem" or "task", as it comprises the various tasks an employee has to perform. Besides rephrasing existing items, we created three new items for the first dimension (domain-specific skills) as it contained two items only. As a result, at least five items tapped into each dimension (Burns et al., 2008).

Finally, all items were analysed one last time for ease of understanding and uniqueness. This was done by administering the questionnaire to five professionals with the request to fill it in and by subsequently discussing with them the clarity of each item. The ensuing results were discussed with two senior researchers experienced in instrument construction and expertise literature. Seven items were removed due to redundancy and four items were rephrased for the sake of clarity. The final instrument consisted of 17 items: items 1-5 tapping into the dimension of domain-specific skills, items 6-9 measuring metacognitive skills, and items 10-17 capturing innovative skills. A 5-point Likert scale, ranging from "strongly disagree" to "strongly agree", was used for all items.

\section{Sample}

Data were collected from the graduate population of a midsized European University and through online professional networks. A total of 216 graduates and 172 professionals completed the survey. The mean age was 36.89 $(S D=11.64) ; 68 \%$ were female; and $54.55 \%$ were from Europe (Figure 2). In line with Shanteau (1992), graduates were considered novices. We specifically selected graduates for this study, as the necessary epistemological perspective can already be present at this early stage of expertise development. In addition, Hatano and Inagaki (1986) argue that indicators for high levels of adaptive expertise can already be present in novices. For this reason, Schwartz et al. (2005) argue for the integration of unfamiliar problems into educational experiences. The selected graduates were taking master's degrees that mixed the acquisition of domain-specific skills with the need to be innovative when solving unfamiliar problems. This means that they had already undergone several experiences that are necessary for the development of adaptive expertise. 


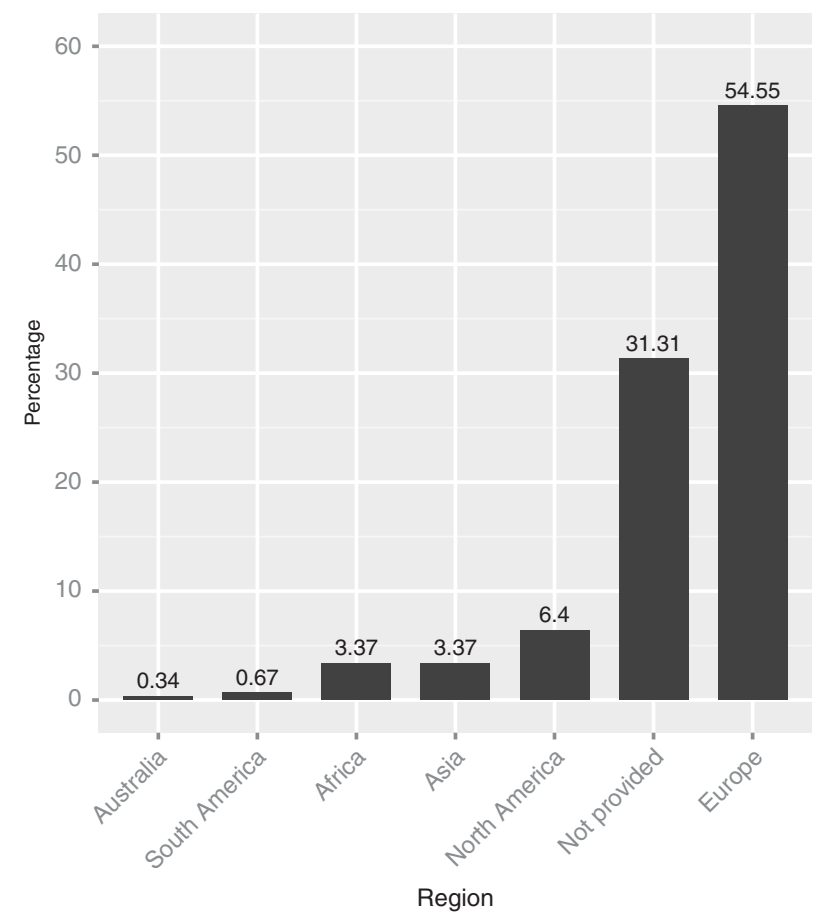

Figure 2. Geographic background of participants.

Professionals had an average work experience of 15 years $(S D=10)$, with $22 \%$ of them having less than 5 years, $15 \%$ between 5 and 10 years, and $63 \%$ over 10 years of work experience. According to the European classification of work domains (EUROSTAT, 2008), most participants were employed in (or aspired to work in) professional, scientific, and technical areas $(40.4 \%)$, or the educational realm (34.44\%) (Figure 3 ). The various work environments were grouped into high-, medium-, and lowvalidity environments using Shanteau (1992) as a guide. Construction, electricity, gas, steam and air conditioning supply, manufacturing, transportation, and storage sectors were classified as high-validity environments. Mediumvalidity environments were financial and insurance, information and communication, other services, and public administration sectors. Lastly, low-validity domains were represented by education, human health and social work sectors, and professional, scientific, and technical activities.

\section{Analysis}

As the goal of the analysis was to probe the underlying structure of the instrument (Fabrigar, Wegener, MacCallum, \& Strahan, 1999), we conducted an EFA and CFA. To do this, the sample was randomly split in two. Samples 1 $(N=191)$ and $2(N=190)$ did not differ in background characteristics (mean age: $t(203)=0.82, p=.41$; gender: $\chi^{2}(1)=0.04, p=.84$; professional: $\chi^{2}(1)=0.03, p=.88$ ).

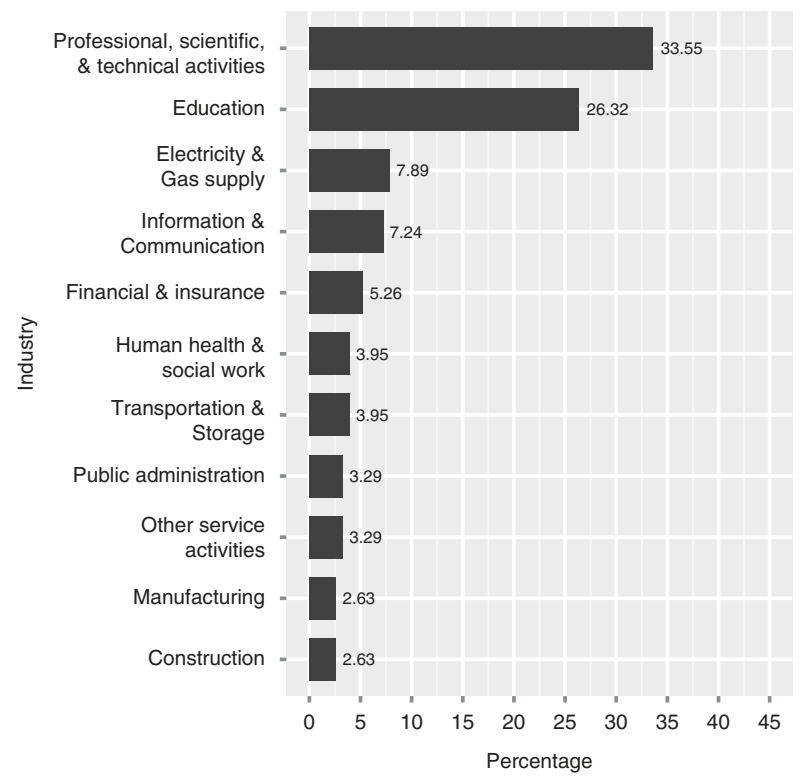

Figure 3. Work domains of participants.

\section{Exploratory factor analysis}

The number of factors to be extracted from the EFA was based on a parallel analysis (Fabrigar et al., 1999; Hayton, Allen, \& Scarpello, 2004). To avoid chances of Type 1 errors and over-factorization, the average of randomly computed eigenvalues was based on the 95th percentile (Glorfeld, 1995). The number of factors that had an adjusted eigenvalue (i.e., eigenvalues corrected for sampling errors due to a small sample size) greater than 0 (Dinno, 2010; Schmitt, 2011) were retained.

Like other researchers (Mattsson, 2012) we have used a polychoric correlation to calculate the factor structure. The reason for this choice was that the survey employed a 5-point Likert scale as answer format. While the underlying latent construct of adaptive expertise may be thought of in continuous terms, it is measured through discrete categories, which take on an ordinal form. For this type of data, polychoric correlations have shown to produce more accurate results than Pearson correlations (Holgado-Tello, Chacón-Moscoso, Barbero-García, \& Vila-Abad, 2010). The factor analysis was conducted using weighted least square (WLS) method, which is based on polychoric correlation and therefore accounts for the ordinal data structure (Schmitt, 2011).

In our decision of the factor structure, we allowed factors to correlate with each other. This lenience can be justified by theory, as higher levels of expertise are generally accompanied by a corresponding rise in metacognitive skills. While theory provides less justification for a correlation between innovative skills and domain-specific skills or metacognitive skills, a case is made for the use of oblique rotation, as it produces a more statistically sound 
factor structure (Schmitt, 2011). As the instrument was based on existing validated instruments, a simple structure was expected with few cross-loadings. Therefore, Bentler$\mathrm{Q}$ rotation was used.

\section{Confirmatory factor analysis}

As with EFA, the confirmatory analysis was conducted using WLS, which is based on polychoric correlation. The factor structure ensuing from the EFA and theory was consequently tested by the CFA. When the EFA yields a final model with good fit criteria but with a few items with significant cross-loadings and similar loadings, theory dictates that such items be attributed to the factor. Once a model had been established, the factor structure was compared between professionals and graduates by testing for weak and strong invariance (van de Schoot, Lugtig, \& Hox, 2012). Weak invariance indicates that the factor loadings are the same across groups and, consequently, that both groups attach the same meanings to the items. Strong invariance points to the equality of intercepts across groups; it indicates whether one group scores systematically higher or lower on item responses compared to the other group.

Following recommendations by Schmitt (2011) and Fabrigar et al. (1999), several indices were used to assess model fit: root mean square error of approximation (RMSEA), standardized root mean square residual (SRMR), and the Tucker Lewis index (TLI). RMSEA should not be higher than .06, whereas SRMR should be below .08 (Schmitt, 2011). A TLI above .90 reflects an acceptable fit, and values above .95 indicate an excellent fit to data (Marsh, Liem, Martin, Morin, \&
Nagengast, 2011). Given the discussion on criteria for cut-off values (Marsh, Hau, \& Wen, 2004), such criteria should not be regarded as golden rules. More emphasis should be placed on a comparison of indices between alternative models.

\section{Results}

\section{Instrument descriptive}

Insight into the quality of the instrument was first gained through a descriptive analysis (see Table 2). Items 14 and 15 were negatively worded and reversed for ease of interpretation. Important for the following analytical step is to note that all items were positively skewed.

With moderate levels of non-normality (defined as skewness of 1.25 and kurtosis of 3.75; Flora \& Curran, 2004) and a sample size of at least 185 responses (determined by $(k+1)(k+2) / 2$; Flora \& Curran, 2004), full WLS can be used. However, as some items revealed higher absolute levels of skewness or kurtosis, we used robust WLS in order to obtain better estimates (Flora \& Curran, 2004). To analyse polychoric correlation, each variable needs to have the same amount of response categories. As in some cases the lowest response category (i.e., the value 1) was not used, for the remaining cases the two lowest response categories (i.e., the values 1 and 2) were merged.

\section{Exploratory factor analysis}

The outcome of the parallel analysis suggested extracting four factors (Figure 4). As theory commands the use of

Table 2. Item descriptives.

\begin{tabular}{|c|c|c|c|c|c|c|c|c|}
\hline & Min & Max & Mean & SD & Skewness & Kurtosis & Normtest.W & Normtest.p \\
\hline Item 1 & 1.00 & 4.00 & 3.18 & 0.78 & -0.73 & 0.13 & 0.81 & 0.00 \\
\hline Item 2 & 1.00 & 4.00 & 2.86 & 0.85 & -0.34 & -0.53 & 0.86 & 0.00 \\
\hline Item 3 & 1.00 & 4.00 & 3.22 & 0.64 & -0.58 & 0.90 & 0.76 & 0.00 \\
\hline Item 4 & 1.00 & 4.00 & 3.40 & 0.70 & -0.92 & 0.23 & 0.75 & 0.00 \\
\hline Item 5 & 1.00 & 4.00 & 3.52 & 0.67 & -1.38 & 1.80 & 0.69 & 0.00 \\
\hline Item 6 & 1.00 & 4.00 & 2.89 & 0.82 & -0.36 & -0.44 & 0.85 & 0.00 \\
\hline Item 7 & 1.00 & 4.00 & 2.79 & 0.77 & -0.30 & -0.23 & 0.85 & 0.00 \\
\hline Item 8 & 1.00 & 4.00 & 2.68 & 0.77 & -0.32 & -0.22 & 0.85 & 0.00 \\
\hline Item 9 & 1.00 & 4.00 & 2.89 & 0.80 & -0.59 & 0.12 & 0.83 & 0.00 \\
\hline Item 10 & 1.00 & 4.00 & 2.88 & 0.83 & -0.61 & 0.01 & 0.83 & 0.00 \\
\hline Item 11 & 1.00 & 4.00 & 3.37 & 0.72 & -0.92 & 0.39 & 0.76 & 0.00 \\
\hline Item 12 & 1.00 & 4.00 & 2.94 & 0.83 & -0.39 & -0.46 & 0.85 & 0.00 \\
\hline Item 13 & 1.00 & 4.00 & 3.08 & 0.76 & -0.49 & -0.20 & 0.83 & 0.00 \\
\hline Item 14 & 1.00 & 3.00 & 1.17 & 0.45 & 2.72 & 6.80 & 0.41 & 0.00 \\
\hline Item 15 & 1.00 & 4.00 & 2.16 & 0.86 & -0.06 & -1.21 & 0.83 & 0.00 \\
\hline Item 16 & 1.00 & 4.00 & 2.73 & 0.71 & -0.79 & 0.61 & 0.77 & 0.00 \\
\hline Item 17 & 1.00 & 4.00 & 3.02 & 0.68 & -0.42 & 0.41 & 0.80 & 0.00 \\
\hline
\end{tabular}

Note: To calculate polychoric correlations, the response categories 1 and 2 have been collapsed, as for some variables the lowest answer option (1) was not used. 


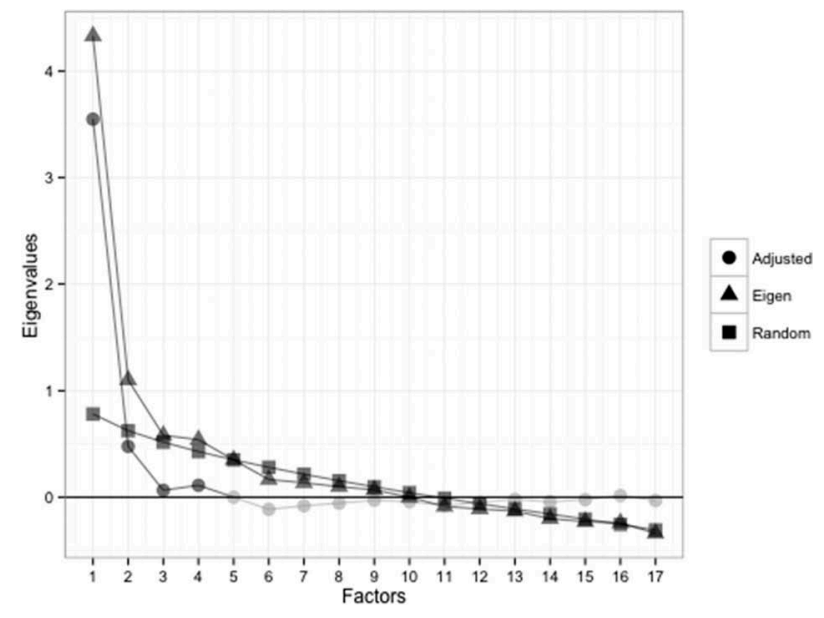

Figure 4. Results of parallel analysis.

three factors, the model analysis was done with three and four factors to determine which provided the best fit.

Neither the three- nor the four-factor model resulted in a good fit (three-factor solution: $R M S E A=.14, T L I=.65$, $B I C=-71.87$, SRMSR: .08; four-factor solution: RMSEA $=.14, T L I=.67, B I C=-71.85$, SRMSR $=.06$ ). In addition, both models appeared to contain weakly defined factors, as these had only two or three items loading on them, which signals a factor's instability (Costello \& Osborne, 2005). Items 9, 10, and 14 were therefore removed, as these loaded on such an unstable factor. This improved the model fit substantially (threefactor solution: $R M S E A=.11, T L I=.81, B I C=-114.47$, $S R M S R=.07$; four-factor solution: $R M S E A=.10$, $T L I=.82, B I C=-95.08, S R M S R=.06)$. The factor structure again showed some complications with the items referring to metacognitive skills. Items 7 and 8 together loaded on one factor and item 6 did not load significantly on any factor. To achieve a good model fit, it was decided to remove items $6,7,8$, and 9 , all of which referred to metacognitive skills. While some researchers have suggested that this dimension is a characteristic of adaptive expertise, not all researchers concurred. What is more, sound evidence of metacognitive skills being a crucial dimension of adaptive expertise is still lacking (Bohle Carbonell et al., 2014).

After having removed a considerable amount of items, we conducted another parallel analysis, the outcome of which suggested a two-factor solution. Considering our previous extraction of three and four factors, we decided to extract two, three, and four factors. All factor solutions appeared to fit the model well (two-factor solution: $R M S E A=.09, T L I=.90, B I C=-96.14, S R M S R=.06$; three-factor solution: $R M S E A=.07, T L I=.94$, $B I C=-84.62$, SRMSR $=.05$; four-factor solution: $R M S E A=.04, T L I=.98, B I C=-67.92, S R M S R=.04)$. As regards factor structures, the two-factor one proved to be the cleanest and best-defined, although the fit criteria were not the highest. The three-factor solution had two moderately defined factors, two items that cross-loaded, and one item with a low loading. The four-factor solution had one moderately defined factor, one weakly defined factor, and two items with a low loading.

The two-factor structure depicted in Table 3 (see columns 2 and 3) indicates one factor for domain-specific skills, as items loading on it only relate to domain-specific skills (items 2-5). The interpretation of the second factor is more problematic, as it contains one item for domainspecific skills (item 1) and five items (items 11-13 and 16-17) measuring innovative skills. The polychoric correlation between these two factors is .45 .

\section{EFA within a CFA framework}

In order to explore the factor structure further, we conducted an E/CFA. This analysis is similar to EFA in that it allows all items to load on all factors. Yet, it is different as it provides more information about significance of cross-loadings and therefore aids the development of a final factor structure. For each factor, we chose an anchor item that had a large primary loading and small cross-loadings (Brown, White, Forsyth, \& Barlow, 2004). Based on the EFA, items 4 and 17 were identified as the anchor items. The model provided an acceptable fit $\left(\chi^{2}(19.32)=31.32, p=.04\right.$, Satarro Bentler correction for non-normal data $=.62 ; R M S E A=.06,90 \%$ $\mathrm{CI}=0-.10 ; T L I=.95, C F I=.88, \mathrm{SRMR}=.04)$. In the EFA, items 1 and 11 loaded moderately on one factor and weakly on the other, whereas in the E/CFA, these exact items appeared to load significantly at $p<.01$ on two factors. Item 15, which did not previously load strongly on any factor, now loaded significantly on the first factor. The two factors showed a polychoric correlation of $.21(p=.25)$. The analysis of the modification indices revealed that none were significant, nor did they have high power (Schmitt, 2011).

So far, the results seem to indicate that adaptive expertise is composed of two dimensions. The results of the data analysis, combined with theory, allow for the making of the careful assumption that metacognitive skills are not a defining characteristic of individuals with adaptive expertise. Given the significant cross-loadings, a CFA model will be fitted which matches the theory of adaptive expertise.

\section{CFA}

Based on the results from the EFA and E/CFA, a model was fitted to Sample 2. As the E/CFA reported that items 1,11 , and 13 had significant cross-loadings, the decision as to what factor the item should load on was guided by theory. Items 1-5 were modelled to load on factor 1 
Table 3. Latent factor structure: EFA and EFA in CFA framework.

\begin{tabular}{|c|c|c|c|c|c|}
\hline \multirow[b]{2}{*}{ Item } & \multicolumn{2}{|c|}{ EFA } & \multicolumn{2}{|c|}{ EFA in CFA } & \multirow[b]{2}{*}{ Item wording } \\
\hline & $\begin{array}{l}\text { Factor } \\
1 \text { (DS) }\end{array}$ & $\begin{array}{l}\text { Factor } \\
2 \text { (IS) }\end{array}$ & $\begin{array}{l}\text { Factor } \\
1 \text { (DS) }\end{array}$ & $\begin{array}{l}\text { Factor } \\
2 \text { (IS) }\end{array}$ & \\
\hline 1 & .31 & .44 & $.25^{*}$ & $.32 * *$ & $\begin{array}{l}\text { During past projects, I was able to develop and integrate new knowledge with what } \\
\text { I learned in the past }\end{array}$ \\
\hline 2 & .56 & .19 & $.46 * *$ & .19 & $\begin{array}{l}\text { During past projects, I concerned myself with the latest development in the domain } \\
\text { of my discipline }\end{array}$ \\
\hline 3 & .70 & .09 & $.37 * *$ & .12 & During past projects, I gained a better understanding of concepts in my discipline \\
\hline 4 & .89 & -.14 & $.52 * *$ & 0 & $\begin{array}{l}\text { During past projects, I realized that the knowledge in my discipline keeps on } \\
\text { developing }\end{array}$ \\
\hline 5 & .78 & -.05 & $.43 * *$ & .04 & $\begin{array}{l}\text { During past projects, I realized that I need to learn continuously to become and stay } \\
\text { an expert in my field }\end{array}$ \\
\hline 11 & .39 & .45 & $.26^{* *}$ & $.32 * *$ & $\begin{array}{l}\text { During past projects, I showed that I am willing to keep on learning new aspects } \\
\text { related to my discipline }\end{array}$ \\
\hline 12 & .15 & .63 & .16 & $.49 * *$ & $\begin{array}{l}\text { During past projects, I applied my knowledge in new and unfamiliar situations in } \\
\text { areas related to my discipline with a degree of success }\end{array}$ \\
\hline 13 & .35 & .45 & $.27 *$ & $.35^{* *}$ & During past projects, I focused on new challenges \\
\hline 15 & -.35 & .12 & $-.25 *$ & .05 & During past projects, I approached it like other projects I worked on in the past \\
\hline 16 & -.18 & .80 & -.04 & $.46^{* *}$ & $\begin{array}{l}\text { During past projects, I was able to keep on performing at a high level when } \\
\text { confronted with unfamiliar situations or tasks }\end{array}$ \\
\hline 17 & -.09 & .78 & 0 & $.45 * *$ & $\begin{array}{l}\text { During past projects, I was able to apply my knowledge flexible to the different } \\
\text { tasks within the project }\end{array}$ \\
\hline \multicolumn{2}{|c|}{ Correlation } & .45 & & .21 & \\
\hline
\end{tabular}

Note: Bold numbers are above the cut-off value of .40; $* p<.01,{ }^{*} p<.001$.

(domain-specific skills) and items $11-13$ and $16-17$ on factor 2 (innovative skills). Item 15 was omitted as it had an insignificant loading for factor 2 . To keep total variance to 1 , the variances of items 1 and 13 were fixed at 1 . The model fitted the data adequately $\left(\chi^{2}(34)=44.24, p=.11\right.$, Satarro Bentler correction for non-normal data $=.27$; RMSEA $=.04,90 \% \mathrm{CI}=0-.07 ; T L I=.89, C F I=.92$, SRMR $=.04)$. After having analysed the modification indices, we added the residual covariance between items 16 and 17 to the model. This resulted in a good model fit $\left(\chi^{2}(33)=34.57, p=.39\right.$, Satarro Bentler correction for non-normal data $=.27 ;$ RMSEA $=.02,90 \% \mathrm{CI}=0-.06$; $T L I=.98, C F I=.99, \mathrm{SRMR}=.04)$. The CFA is reported in Table 4.

The results of the multi-group analysis comparing the factor structures of graduates and professionals are reported in Table 5. In model 1, we kept the factor structure consistent for both groups. An ensuing significance of model 1 would imply that professionals and graduates have the same factor structure. In the second model, both factor structure and item loadings were kept equal for each group. A comparison between models 1 and 2 did not yield any significant difference, from which we can infer that weak invariance exists. Hence, professionals and graduates did not vary in their factor structure and item loadings. As regards model 3, we kept item loadings and intercepts equal across groups. The results of models 2 and 3 varied significantly: Model 3 yielded lower fit indices. Therefore, it can be concluded that invariance was not strong. That is, the groups did vary in their factor loadings and intercepts. Thus, there were systematic differences between the responses of professionals and graduates.

Before analysing the predictors of adaptive expertise, we assessed the reliability of the instrument. The final instrument, the Adaptive Expertise Inventory, consists of two subscales with five items each. Table 6 details the Cronbach's alphas for each of these subscales: They range from .74 to .85 . Some of the figures are slightly lower than the generally acceptable value of .80 , but in early stages of research, such lower levels are permitted (Lance, 2006).

\section{Validity of environments and levels of adaptive expertise}

The classification of work domains into low-, medium-, and high-validity resulted in 14 professionals who were employed in high-validity, 84 in medium-validity, and 19 in low-validity environments. Fifty-five professionals did not indicate their work environment. Graduates were excluded from this analysis considering their lack of relevant work experience.

Figure 5 maps the scores on the Adaptive Expertise Inventory according to work environment. As expected, professionals in high-validity environments have the lowest mean score. However, the mean scores for professionals in medium- and low-validity environments do not differ. In all environments, outliers are present. On the whole, we can conclude that the Adaptive Expertise 
Table 4. Latent factor structure: standardized loadings from CFA.

\begin{tabular}{|c|c|c|c|c|c|c|}
\hline & \multicolumn{2}{|c|}{ Sample $2(\mathrm{~N}=190)$} & \multicolumn{2}{|c|}{ Professionals $(\mathrm{N}=172)$} & \multicolumn{2}{|c|}{ Graduates $(\mathrm{N}=211)$} \\
\hline & DS & IS & DS & IS & DS & IS \\
\hline Item 1 & & .68 & & .61 & & .56 \\
\hline Item 2 & & .70 & & .71 & & .69 \\
\hline Item 3 & & .68 & & .72 & & .68 \\
\hline Item 4 & & .65 & & .58 & & .64 \\
\hline Item 5 & & .60 & & .62 & & .57 \\
\hline Item 11 & .74 & & .65 & & .71 & \\
\hline Item 12 & .66 & & .70 & & .57 & \\
\hline Item 13 & .68 & & .74 & & .69 & \\
\hline Item 16 & .50 & & .36 & & .60 & \\
\hline Item 17 & .63 & & .39 & & .66 & \\
\hline Correlation DS-IS & .29 & & .23 & & .21 & \\
\hline$\chi^{2}$ & & & 63.61 & & 31.04 & \\
\hline
\end{tabular}

Notes: DS, domain skills; IS, innovative skills.

Table 5. Test of measurement invariance.

\begin{tabular}{lcccccc}
\hline & $\chi^{2}$ & df & p & CFI & RMSEA & BIC \\
\hline $\begin{array}{l}\text { Model 1: same factor } \\
\quad 138.14\end{array}$ & 66 & .00 & 0.94 & 0.08 & 7914.96 \\
$\quad$ structure & & & & & & \\
$\begin{array}{l}\text { Model 2: same item } \\
\quad \text { loadings }\end{array}$ & 149.09 & 74 & .00 & .93 & .07 & 7878.32 \\
$\begin{array}{l}\text { Model 3: same item } \\
\text { loadings and } \\
\text { intercepts }\end{array}$ & 195.90 & 82 & .00 & .90 & .09 & 7877.55 \\
$\begin{array}{l}\text { Test for weak } \\
\text { invariance }\end{array}$ & 10.95 & 8 & .21 & & & \\
$\begin{array}{l}\text { ANOVA (model 1 vs. } \\
\text { model 2) }\end{array}$ & & & & & & \\
$\begin{array}{l}\text { Test for strong } \\
\text { invariance }\end{array}$ & 57.76 & 16 & .00 & & & \\
$\begin{array}{l}\text { ANOVA (model 1 vs. } \\
\text { model 3) }\end{array}$ & & & & & & \\
\hline
\end{tabular}

Table 6. Cronbach's alpha for the adaptive expertise inventory and its subscales.

\begin{tabular}{lccc}
\hline & $\begin{array}{c}\text { Complete sample } \\
(\mathrm{N}=383)\end{array}$ & $\begin{array}{c}\text { Professionals } \\
(\mathrm{N}=172)\end{array}$ & $\begin{array}{c}\text { Graduates } \\
(\mathrm{N}=211)\end{array}$ \\
\hline $\begin{array}{c}\text { Adaptive } \\
\text { expertise }\end{array}$ & .85 & .82 & .85 \\
$\begin{array}{c}\text { Domain } \\
\text { skills }\end{array}$ & .79 & .79 & .77 \\
$\begin{array}{c}\text { Innovative } \\
\text { skills }\end{array}$ & .78 & .74 & .78 \\
\hline
\end{tabular}

Inventory is able to differentiate between high-validity domains on the one hand and medium- and low-validity domains on the other, but not between these latter two environments. The expectation that the score on the

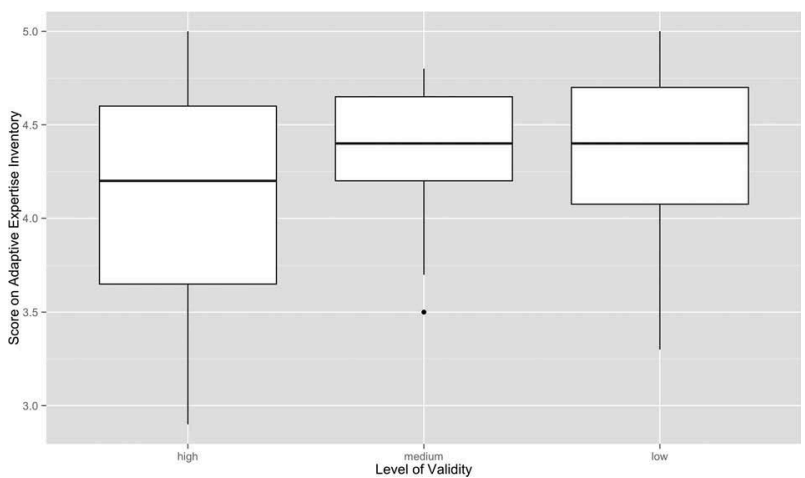

Figure 5. Box plot mapping scores on the adaptive expertise inventory according to the validity of the domain.

Adaptive Expertise Inventory increases with decreasing validity can therefore only be partially supported.

\section{Predictors of adaptive expertise}

In order to assess criterion-related validity of the scale, task variety and years of work experience were regressed on the scores of the Adaptive Expertise Inventory. Given the nature of the predictors, this analysis was only conducted with the professional sample. Adaptive expertise had a mean score of $4.32(S D=0.46)$, ranging from 2.9 to 5.0. The mean score on domain-specific skills was 4.42 $(S D=0.55)$, ranging from 2.8 to 5.0 , whereas innovative skills had a mean score of $4.22(S D=0.52)$ with a range of 2.2-5.0. The mean for task variety was 3.47 $(S D=0.94)$. Adaptive expertise scores had a Pearson correlation with task variety of $.32(p<.001)$ and work experience of $.25(p<.01)$. Task variety and work experience correlated at $.25(p<.01)$. The standardized regression coefficients of the analysis are reported in Table 7. 
Table 7. Results of the regression analysis of task variety and work years on adaptive expertise (standardized coefficients).

\begin{tabular}{lcll}
\hline Dependent variable & \multirow{2}{*}{$\mathrm{R}^{2}$} & \multicolumn{1}{c}{ Independent variable } & $\beta$ \\
\hline Adaptive expertise & $.11^{* * *}$ & Task variety & $.26^{* * *}$ \\
& & Work experience (in years) & .16 \\
Domain skills & $.12^{* * *}$ & Task variety & $.24^{*}$ \\
& & Work experience (in years) & $.20^{*}$ \\
Innovative skills & $.05^{*}$ & Task variety & $.21^{*}$ \\
& & Work experience (in years) & .08 \\
\hline
\end{tabular}

Notes: $N=155,{ }^{*} p<.01,{ }^{* *} p<.001,{ }^{* * *} p<.0001$.

The model was significant $(F(2,152)=10.89, p<.0001)$. As predicted by theory, task variety had a significant and positive relationship with the adaptive expertise score $(\beta=.26, p<.01)$. Looking deeper into its effect, we found task variety to correlate positively with both domain-specific and innovative skills $(\beta=.24, p<.01$ and $\beta=.21, p<.01$ respectively). Contrary to the expectation that adaptive expertise score would rise with increased work experience, the latter bore a relation to domain-specific skills only $(\beta=.20, p<.01)$ and none to the adaptive expertise score and innovative skills.

\section{Discussion}

This study departed from the desire to fill both a theoretical and a practical void: the necessity for an instrument that measures adaptive expertise and fits its theoretical conceptualization. Such an instrument is needed not only to advance the understanding of adaptive expertise, but also to help organizations assess their workforce's readiness to deal with non-standard situations. Based on the literature, three dimensions (domain-specific skills, metacognitive skills, and innovative skills) were hypothesized to be part of adaptive expertise. The results of the CFA revealed that an instrument with only two dimensionsdomain-specific and innovative skills-fit the model well. This two-factor structure matched the empirical evidence about domain-specific and innovative skills being part of adaptive expertise. The postulate that metacognitive skills are a critical dimension of adaptive expertise, however, could not be confirmed.

The factor structure was stable across the two populations in the sample (professionals and graduates), providing evidence that the instrument measures the same concept in professionals and graduates. In addition, the instrument proved to be able to differentiate between professionals and graduates, as shown by the lack of strong invariance. Graduates are novices (given their lack of theoretical domain knowledge and work experience) and thus will have lower scores on the Adaptive Expertise Inventory than professionals. This seems to suggest that, although graduates do not perform at an expert level on regular tasks, the skills needed to achieve high scores are already present in a rudimentary form.

The results only partially supported the expectation that the score on the Adaptive Expertise Inventory would increase with decreasing validity. While experts in highvalidity environments scored lower than their counterparts in low- and medium-validity environments, a noticeable difference between experts in low- and medium-validity environments could not be detected. In addition, the difference between mean scores was small, indicating that the instrument could benefit from further refinement.

As task variety had a positive relationship adaptive expertise score, criterion validity was established. This provides further evidence that the instrument reliably measures adaptive expertise. The finding that level of adaptive expertise is a positive and significant function of task variety is also important for the development of adaptive expertise. It indicates that employees are better served by task variation. In addition, as years of work experience bore a relationship to domain-specific skills only, and not to level of adaptive expertise, these findings indicate that adaptive expertise is not acquired automatically. The results also imply that, generally, employees who have several years of work experience can gain adaptive expertise if their innovative skills are stimulated.

Drawing on the conceptualization of adaptive expertise as described by Hatano and Inagaki (1986), the Adaptive Expertise Inventory aids future research into adaptive expertise. First, the ability to measure adaptive expertise allows researchers to look into the degree of adaptation that adaptive experts can master. The question then is: Within what range of novelty of a task vis-à-vis the original task can we still reasonably expect an individual with adaptive expertise to complete it? Second, the ability to measure levels of adaptive expertise, together with the knowledge that task variety influences it, makes it possible to evaluate development programmes that aim to stimulate the development of adaptive expertise in employees and, by that, contribute to the design of more effective programmes.

Although the instrument stretches the field of adaptive expertise further, some of its limitations should be kept in mind, the first one being its heterogeneous sample and modest sample size. While the factor structure was stable across groups of participants (graduates and professionals), findings were based on responses by a modest number of professionals. Thus, statistics could have been dominated by the graduate population. To bolster confidence in the instrument's validity, future research with a larger sample size is necessary to eliminate the possibility of measurement outcomes being affected by the sampling technique used. Second, reliability figures for the two subscales are approaching .80 . This indicates that there is 
scope for further improvement. Third, the lowest score on the Adaptive Expertise Inventory is 2.9. This raises concerns for the instrument's ability to discriminate between high and medium levels of adaptive expertise. In addition, the instrument's ability to distinguish between the level of adaptive expertise of professionals working in low-, medium-, and high-validity environments is limited. As we would expect the level of adaptive expertise to differ according to the validity of an environment, the instrument should be able to capture this. Therefore, it is important to first establish if the factor structure holds for work environments with different levels of validity.

To improve construct validity, experts should be interviewed about their experience with non-standard tasks. This would lead to a collection of critical incidents, that is, situations in which the individual is confronted with an unfamiliar problem and successful strategies to deal with these situations. These could subsequently be compared with the items on the Adaptive Expertise Inventory, providing opportunity to refine these, if necessary. To assess criterion validity of the Adaptive Expertise Inventory, it is necessary to observe individuals performing non-standard domain tasks with divergent scores on the Adaptive Expertise Inventory. Domain experts should select these tasks to ensure that they are indeed unfamiliar. The proposed design would resemble the study by Barnett and Koslowski (2002) and would allow researchers to compare task performance with the Adaptive Expertise Inventory score. Experts with higher scores should also reveal a better performance on these tasks.

Regardless of the strategy chosen, attention has to be paid to the domain's level of validity of participating professionals. This is necessary to develop domain-specific and innovative skill items that better nuance between the validity levels of work environments.

The study aimed to create a valid instrument that measures individual levels of adaptive expertise. The newly developed Adaptive Expertise Inventory consists of two scales-domain-specific and innovative skillsconsistent with theory. Its factor structure is stable across populations in different stages of their career, and also able to discriminate between novices and experts. It confirms the superiority of task variety to years of work experience as regards its importance for adaptive expertise. The Adaptive Expertise Inventory can benefit both organizations, by measuring their employees' readiness to tackle non-standardized tasks, and researchers, by delivering them a tool with which to measure adaptive expertise and consequently gain further insight into the respective concept.

\section{Disclosure statement}

No potential conflict of interest was reported by the authors.

\section{Funding}

This work was supported by the Ministerie van Onderwijs, Cultuur en Wetenschappen.

\section{References}

Alexander, P. A., Schallert, D. L., \& Hare, V. C. (1991). Coming to terms: How researchers in learning and literacy talk about knowledge. Review of Educational Research, 61, 315-343. doi:10.3102/00346543061003315

Allworth, E., \& Hesketh, B. (1999). Construct-oriented biodata: Capturing change-related and contextually relevant future performance. International Journal of Selection and Assessment, 7, 97-111. doi:10.1111/1468-2389.00110

Barnett, S., \& Koslowski, B. (2002). Adaptive expertise: Effects of type of experience and the level of theoretical understanding it generates. Thinking \& Reasoning, 8, 237-267. doi:10.1080/13546780244000088

Bell, B. S., \& Kozlowski, S. W. J. (2008). Active learning: Effects of core training design elements on self-regulatory processes, learning, and adaptability. The Journal of Applied Psychology, 93, 296-316. doi:10.1037/0021-9010.93.2.296

Bohle Carbonell, K., Stalmeijer, R. E., Könings, K. D., Segers, M., \& Van Merriënboer, J. J. G. (2014). How experts deal with novel situations: A review of adaptive expertise. Educational Research Review, 12, 14-29. doi:10.1016/j. edurev.2014.03.001

Bransford, J. D., \& Schwartz, D. (2009). It takes expertise to make expertise: Some thoughts about why and how and reflections on the themes. In K. A. Ericsson (Ed.), Development of professional expertise: Toward measurement of expert performance and design of optimal learning environments (pp. 432-448). Cambridge: Cambridge University Press.

Brown, T. A., White, K. S., Forsyth, J. P., \& Barlow, D. H. (2004). The structure of perceived emotional control: Psychometric properties of a revised anxiety control questionnaire. Behavior Therapy, 35, 75-99. doi:10.1016/ S0005-7894(04)80005-4

Burns, K. E. A., Duffett, M., Kho, M. E., Meade, M. O., Adhikari, N. K. J., Sinuff, T., \& Cook, D. J. (2008). A guide for the design and conduct of self-administered surveys of clinicians. Canadian Medical Association Journal, 179, 245-252. doi:10.1503/cmaj.080372

Chan, D. (2000). Conceptual and empirical gaps in research on individual adaptation at work. In I. T. Robertson \& C. L. Cooper (Eds.), International review of industrial and organizational psychology (pp. 143-164). New York, NJ: Wiley.

Charbonnier-Voirin, A., \& Roussel, P. (2012). Adaptive performance: A new scale to measure individual performance in organizations. Revue Canadienne Des Sciences de l'Administration [Canadian Journal of Administrative Sciences], 29, 280-293. doi:10.1002/cjas.232

Chi, M. T. H. (2011). Theoretical perspectives, methodological approaches, and trends in the study of expertise. In Y. Li \& G. Kaiser (Eds.), Expertise in mathematics instruction: An international perspective (pp. 17-39). New York, NJ: Springer. doi:10.1007/978-1-4419-7707-6_2.

Costello, A. B., \& Osborne, J. W. (2005). Best practices in exploratory factor analysis: Four recommendations for getting the most from your analysis. Practical Assessment, Research \& Evaluation, 10(7), 1-9. Retrieved from http:// pareonline.net/pdf/v10n7.pdf 
Crawford, V. M., Schlager, M., Toyama, Y., Riel, M., \& Vahey, P. (2005, April 11-15). Characterizing adaptive expertise in science teaching. Paper presented at the annual conference of the American Educational Research Association, Montreal.

Dane, E. (2010). Reconsidering the trade-off between expertise and flexibility: A cognitive entrenchment perspective. Academy of Management Review, 35, 579-603. doi:10.5465/AMR.2010.53502832

Dinno, A. (2010). Gently clarifying the application of Horn's parallel analysis to principal component analysis versus factor analysis. Retrieved from http://doyenne.com/ Software/files/PA_for_PCA_vs_FA.pdf

EUROSTAT. (2008). Statistical classification of economic activities in the European community, rev. 2 [code book]. Retrieved from http://ec.europa.eu/eurostat/ramon/nomenclatures/index.cfm

Fabrigar, L. R., Wegener, D. T., MacCallum, R. C., \& Strahan, E. J. (1999). Evaluating the use of exploratory factor analysis in psychological research. Psychological Methods, 4, 272-299. doi:10.1037/1082-989x.4.3.272

Feltovich, P. J., Prietula, M. J., \& Ericsson, K. A. (2006). Studies of expertise from psychological perspectives. In K. A. Ericsson, N. Charness, P. J. Feltovich, \& R. R. Hoffman (Eds.), The Cambridge handbook of expertise and expert performance (pp. 41-67). New York, NY: Cambridge University Press.

Fisher, F. T., \& Peterson, P. L. (2001, June 24-27). A tool to measure adaptive expertise in biomedical engineering students. Proceedings of the American Society for Engineering Education, Albuquerque (pp. 1249-1263).

Flora, D. B., \& Curran, P. J. (2004). An empirical evaluation of alternative methods of estimation for confirmatory factor analysis with ordinal data. Psychological Methods, 9, 466-491. doi:10.1037/1082-989X.9.4.466

Gentner, D., Brem, S., Ferguson, R. W., Markman, A. B., Levidow, B. B., Wolff, P., \& Forbus, K. D. (1997). Analogical reasoning and conceptual change: A case study of Johannes Kepler. Journal of the Learning Sciences, 6, 3-40. doi:10.1207/s15327809j1s0601_2

Glorfeld, L. W. (1995). An improvement on Horn's parallel analysis methodology for selecting the correct number of factors to retain. Educational and Psychological Measurement, 55, 377-393. doi:10.1177/00131644950 55003002

Grenier, R. S., \& Kehrhahn, M. (2008). Toward an integrated model of expertise redevelopment and its implications for HRD. Human Resource Development Review, 7, 198-217. doi: $10.1177 / 1534484308316653$

Hatano, G., \& Inagaki, K. (1986). Two courses of expertise. In H. Stevenson, H. Azuma, \& K. Hakuta (Eds.), Child development and education in Japan (pp. 262-272). New York, NY: W. H. Freeman.

Hatano, G., \& Oura, Y. (2003). Commentary: Reconceptualizing school learning using insight from expertise research. Educational Researcher, 32, 26-29. doi:10.3102/ 0013189X032008026

Hayton, J. C., Allen, D. G., \& Scarpello, V. (2004). Factor retention decisions in exploratory factor analysis: A tutorial on parallel analysis. Organizational Research Methods, 7, 191-205. doi:10.1177/1094428104263675

Holgado-Tello, F. P., Chacón-Moscoso, S., Barbero-García, I., \& Vila-Abad, E. (2010). Polychoric versus Pearson correlations in exploratory and confirmatory factor analysis of ordinal variables. Quality \& Quantity, 44, 153-166. doi:10.1007/ s11135-008-9190-y
Hughes, M. G., Day, E. A., Wang, X., Schuelke, M. J., Arsenault, M. L., Harkrider, L. N., \& Cooper, O. D. (2013). Learnercontrolled practice difficulty in the training of a complex task: Cognitive and motivational mechanisms. The Journal of Applied Psychology, 98, 80-98. doi:10.1037/a0029821

Kahneman, D., \& Klein, G. (2009). Conditions for intuitive expertise: A failure to disagree. The American Psychologist, 64, 515-526. doi:10.1037/a0016755

Lance, C. E. (2006). The sources of four commonly reported cutoff criteria: What did they really say? Organizational Research Methods, 9, 202-220. doi:10.1177/1094428 105284919

Marsh, H. W., Hau, K.-T., \& Wen, Z. (2004). In search of golden rules: Comment on hypothesis-testing approaches to setting cutoff values for fit indexes and dangers in overgeneralizing $\mathrm{Hu}$ and Bentler's (1999) findings. Structural Equation Modeling: A Multidisciplinary Journal, 11, 320-341. doi:10.1207/s15328007sem1103 2

Marsh, H. W., Liem, G. A. D., Martin, A. J., Morin, A. J. S., \& Nagengast, B. (2011). Methodological measurement fruitfulness of exploratory structural equation modeling (ESEM): New approaches to key substantive issues in motivation and engagement. Journal of Psychoeducational Assessment, 29, 322-346. doi:10.1177/0734282911406657

Martin, L., \& Schwartz, D. L. (2009). Prospective adaptation in the use of external representations. Cognition and Instruction, 27, 370-400. doi:10.1080/07370000903221775

Martin, T., Petrosino, A. J., Rivale, S., \& Diller, K. R. (2006). The development of adaptive expertise in biotransport. New Directions for Teaching and Learning, 2006, 35-47. doi: $10.1002 / \mathrm{tl} .254$

Martin, T., Rivale, S. D., \& Diller, K. R. (2007). Comparison of student learning in challenge-based and traditional instruction in biomedical engineering. Annals of Biomedical Engineering, 35, 1312-1323. doi:10.1007/s10439-0079297-7

Mattsson, M. (2012). Investigating the factorial invariance of the 28-item DBQ across genders and age groups: An exploratory structural equation modeling study. Accident Analysis \& Prevention, 48, 379-396. doi:10.1016/j.aap.2012.02.009

Mylopoulos, M., \& Regehr, G. (2009). How student models of expertise and innovation impact the development of adaptive expertise in medicine. Medical Education, 43, 127-132. doi:10.1111/j.1365-2923.2008.03254.x

Mylopoulos, M., \& Scardamalia, M. (2008). Doctors' perspectives on their innovations in daily practice: Implications for knowledge building in health care. Medical Education, 42, 975-981. doi:10.1111/j.1365-2923.2008.03153.x

Mylopoulos, M., \& Woods, N. N. (2009). Having our cake and eating it too: Seeking the best of both worlds in expertise research. Medical Education, 43, 406-413. doi:10.1111/ j.1365-2923.2009.03307.x

Nahapiet, J., \& Ghoshal, S. (1998). Social capital, intellectual capital, and the organizational advantage. The Academy of Management Review, 23, 242-266. doi:10.1016/B978-07506-7222-1.50009-X

Olsen, S. E., \& Rasmussen, J. (1989). The reflective expert and the prenovice: Notes on skill-, rule-, and knowledge-based performance in the setting of instruction and training. In L. Bainbridge \& S. A. Ruiz-Quintanilla (Eds.), Developing skills with information technology (pp. 9-33). Chichester: Wiley.

Pulakos, E. D., Arad, S., Donovan, M. A., \& Plamondon, K. E. (2000). Adaptability in the workplace: Development of a taxonomy of adaptive performance. Journal of Applied Psychology, 85, 612-624. doi:10.1037/0021-9010.85.4.612 
Reder, L. M., \& Schunn, C. D. (1999). Bringing together the psychometric and strategy worlds: Predicting adaptivity in a dynamic task. In D. Gopher \& A. Koriat (Eds.), Attention and performance XVII: Cognitive regulation of performance: Interaction of theory and application (pp. 315-342). Cambridge, MA: MIT Press.

Schmitt, T. A. (2011). Current methodological considerations in exploratory and confirmatory factor analysis. Journal of Psychoeducational Assessment, 29, 304-321. doi:10.1177/ 0734282911406653

Schwartz, D. L., Bransford, J. D., \& Sears, D. (2005). Innovation and efficiency in learning and transfer. In J. P. Mestre (Ed.), Transfer of learning from a modern multidisciplinary perspective (pp. 1-51). Greenwich, CT: Information Age Publishing.

Shanteau, J. (1992). Competence in experts: The role of task characteristics. Organizational Behavior and Human Decision Processes, 53, 252-266. doi:10.1016/0749-5978 (92)90064-E

Sonnentag, S., Niessen, C., \& Volmer, J. (2006). Expertise in software design. In K. A. Ericsson, N. Charness, P. J. Feltovich, \& R. R. Hoffman (Eds.), The Cambridge handbook of expertise and expert performance. New York, NJ: Cambridge University Press.
Stokes, C. K., Schneider, T. R., \& Lyons, J. B. (2010). Adaptive performance: A criterion problem. Team Performance Management, $\quad 16, \quad 212-230 . \quad$ doi:10.1108/135275910 11053278

Tynjälä, P., Nuutinen, A., Eteläpelto, A., Kirjonen, J., \& Remes, P. (1997). The acquisition of professional expertise-A challenge for educational research. Scandinavian Journal of Educational Research, 41, 475-494. doi:10.1080/ 0031383970410318

van de Schoot, R., Lugtig, P., \& Hox, J. (2012). A checklist for testing measurement invariance. European Journal of Developmental Psychology, 9, 486-492. doi:10.1080/ 17405629.2012.686740

van der Heijden, B. I. J. M. (2000). The development and psychometric evaluation of a multidimensional measurement instrument of professional expertise. High Ability Studies, 11, 9-39. doi:10.1080/713669175

Varpio, L., Schryer, C. F., \& Lingard, L. (2009). Routine and adaptive expert strategies for resolving ICT mediated communication problems in the team setting. Medical Education, 43, 680-687. doi:10.1111/j.1365-2923.2009.03395.x

Wineburg, S. (1998). Reading Abraham Lincoln: An expert/expert study in the interpretation of historical texts. Cognitive Science, 22, 319-346. doi:10.1207/s15516709 $\operatorname{cog} 2203$ _ 3 